\title{
Steam-based Charging-Discharging of a PCM Heat Storage
}

\author{
Asfafaw H. Tesfay ${ }^{1 *}$, Mulu B. Kahsay ${ }^{1}$ and Ole J. Nydal ${ }^{2}$ \\ ${ }^{1}$ School of Mechanical and Industrial Engineering, Ethiopian Institute of Technology-Mekelle, \\ Mekelle University, P.O. Box 231, Mekelle, Ethiopia (*asfafaw.haileslassie@mu.edu.et). \\ ${ }^{2}$ Department of Energy and Process Engineering, Norwegian University of Science and \\ Technology, 7491 Trondheim, Norway.
}

\begin{abstract}
Latent heat storage and efficient heat transport technology helps to utilize the intermittent solar energy for continuous and near isothermal applications. However, many latent heat storages face challenges of storage charging, heat retaining, and discharging the stored heat. This paper tries to address the challenges of heat transportation and storage charging-discharging issues. The heat transportation from the receiver over some distance, from outside to the kitchen, is carried out with a stainless pipeline and water as heat transfer fluids. However, the charging-discharging process is carried by conduction method with the help of fins. In addition, the stored heat is retained for about one-two days by using aerogel insulation. The latent heat is stored in a phase change material (PCM), nitrate salt (mixture of $60 \% \mathrm{NaNO}_{3}$ and $40 \% \mathrm{KNO}_{3}$ ), which melts at $222^{\circ} \mathrm{C}$ and has $109 \mathrm{~J} / \mathrm{g}$ specific heat of fusion. The storage has the capacity of storing up to $250^{\circ} \mathrm{C}$ heat and supply this heat isothermally during baking in the liquid-solid phase transition. However, the sensible heat stored in the solid and liquid form of the PCM is used to perform additional applications that do not require uniform heat which includes bread baking, kita (large pancake) baking and water boiling. The low thermal conductivity of PCM is enhanced by using extended aluminum fins that are attached to the baking plate and extruded inward to the storage. In this paper, two-phase loop thermosyphon of steam is used to manage the long distance heat transportation required between the receiver (outside) and the storage (inside a house). The steam in the thermosyphon flow has restricted to a maximum working temperature of $250^{\circ} \mathrm{C}$. Steam is selected for its highest heat capacity, availability and stable nature. It carries heat from the collector focus point and condenses in a coiled pipe imbedded in aluminum plate placed on top of the storage. Many fins are solidly attached to this plate to conduct the heat down to the PCM inside the storage during charging. This design configuration avoids pressure development inside the PCM storage and the charging-discharging temperature is recorded in three zones (top, middle and bottom) of the storage. The experimental and numerical results show that the heat transportation, retention and charging-discharging methods are effective.
\end{abstract}

Keywords: Solar energy, PCM storage, Latent heat storage, Two-phase thermosyphon.

\section{INTRODUCTION}

Solar thermal energy can be stored by using sensible heat storage (SHS) or latent heat storage (LHS) using a Phase change material (PCM). The stored heat can be used for different applications such as cooking, space heating, hot water supply etc. Latent heat storage provides higher storage capacity, compact size, and nearly isothermal heat supply. However, SHS such as 
rock bed, water, oil etc., are larger storage and have faster temperature decay compared to LHS of the same capacity. These characteristics of SHS have improved by combining PCM material in their design as studied by Okello et al. (2014). Latent heat storage using phase change materials (PCMs) can be designed to have much higher energy storage density than the sensible heat storage (Kuravi et al., 2013). Generally, PCMs have low thermal conductivities and they took longer time of charging (Hussain et al., 2008). Many methods have been proposed to increase the thermal conductivity of PCMs (Tanvir et al., 2015). The finned tube configuration, metal structure insertion into the PCMs, and dispersion of thermally conductive Nano or micro particles within the PCM matrix are some of the widely studied approaches used to improve the charging time of PCMs (Tanvir et al., 2015). In addition to thermal conductivity, mass flow rate and inlet temperature of the heat transfer fluid (HTF) has also affected the charging-discharging process (Abduljalil et al., 2014). PCM charging-discharging process can be improved by designing multi stage storages with different thermos-physical properties (Taha et al., 2014). Furthermore, it can be improved by using fast flowing HTF instead of slow flowing HTF (Robyne et al., 2014). On the other hand, there is a pressure build-up concern associated with PCMs due to the expansion of air at elevated temperatures and due to volume change of the PCMs. The design of this paper has tried to avoid any possible contact between the HTF and PCM and possibilities of pressure buildup by providing a $10 \%$ extra volume.

The objective of this paper is to develop thermal energy storage to store the surplus solar energy during the day and keep it for later, late evening or early morning, use by supplying nearly isothermal heat during discharging. To realize this, two-phase closed loop thermosyphon based heat transfer has used to charge the PCM storage. This design provides threshold height difference between evaporator and condenser of the thermosyphon loop to initiate natural circulation by density difference. Two-phase closed loop thermosiphon has selected because it is capability of transferring heat from a heat source to a separate heat sink over some distance (Alessandro and Sauro, 2013). This heat transfer mechanism is used in many applications such as nuclear cooling and electronic cooling (Zhang et al., 2014). However, this method of charging thermal storage has rarely employed in small-scale applications such as cooking. The present study was focused to give solutions to the alarming deforestation, energy poverty, and related ecological impacts of developing countries associated with intensive cooking. The cooking application experimented in this paper's design is only on Injera and bread baking. 


\section{METHODOLOGY AND MATERIALS}

The methodology followed in this study includes identification of appropriate PCM material that has a solid-liquid phase transition temperature of $222^{\circ} \mathrm{C}$, storage design, thermal analysis, modeling and simulation, prototype development and test.

\subsection{Phase Change Material}

The PCM used in the experiment of this study is $20 \mathrm{~kg}$ of solar salt (nitrate salt mixture $40 \%$ $\mathrm{KNO}_{3}$ and $60 \% \mathrm{NaKO}_{3}$ ). For computational simplicity, the latent heat has described in terms of an effective heat capacity in a narrow temperature range of melting (Foong et al., 2011).

$$
Q=\int_{T_{i}}^{T_{f}} m C_{p} \mathrm{dT}
$$

$$
C_{P}[k J / k g]= \begin{cases}0.75 & T<110^{\circ} \mathrm{C} \\ 4.2 & 110^{\circ} \mathrm{C} \leq T \leq 120^{\circ} \mathrm{C} \\ 1.4 & 120^{\circ} \mathrm{C}<T<210^{\circ} \mathrm{C} \\ 12 & 210^{\circ} \mathrm{C} \leq T \leq 220^{\circ} \mathrm{C} \\ 1.6 & T>220^{\circ} \mathrm{C}\end{cases}
$$

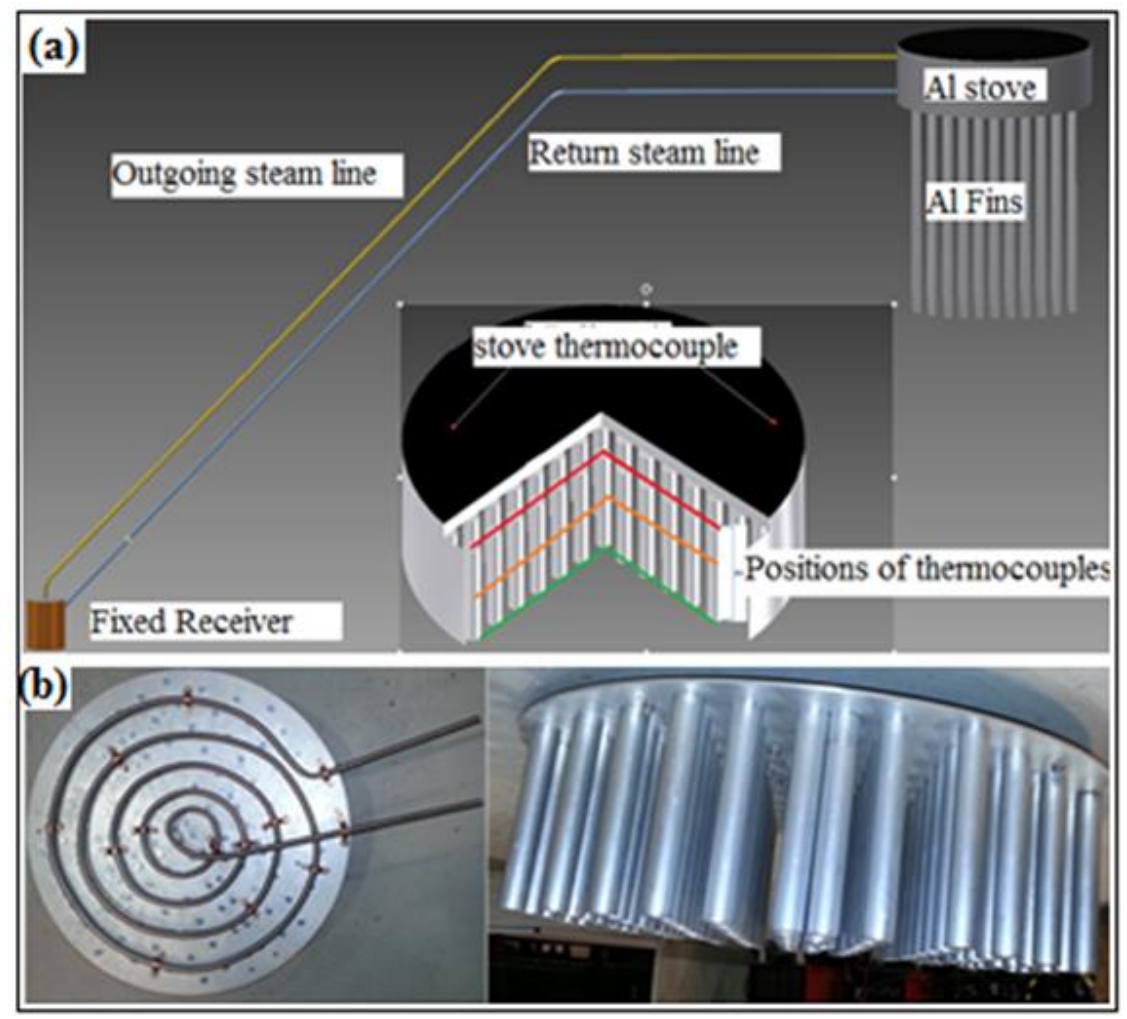

Figure 1. Design and development process of a PCM storage, (a) thermosiphon loop and position of thermocouples within the storage, and (b) top and side view of the storage before casting. 


\subsection{Storage design}

The PCM storage is designed to be charged by a two-phase self-circulating closed loop heat carrier, a polar mounted parabolic dish with sun tracker, a fixed receiver is designed to act as an evaporator and aluminum casted plate with extruded fins down to the PCM is placed on top of the storage. Water is used as heat transfer fluid and the receiver converts this water in to steam. Schematic and actual picture of the system is shown in figure 1.

The Al plate is an embedded stainless steel (SS) steam pipe that acts as heating element. The heat storage is coupled to parabolic dish filmed with $5 \mathrm{~cm}$ glass tiles. The polar mounted technique of the concentrator's design gave a suitable platform for the fixed receiver. This concentrator is coupled to PCM storage with a thermosyphon loop. The system is tested on a real sun and artificial heating to charge the storage. In this experiment, K-type thermocouples, pressure gage, and photo sensors are used to measure temperature distribution, regulate steam pressure and control the tracking mechanisms of the system respectively. The complete list of items is given in table 1 .

Table 1. System instruments and sensors.

\begin{tabular}{|llll|}
\hline Label & Description & Label & Description \\
\hline A & Pressure relief valve & F & Inlet, out let and directional control valves \\
\hline B & Pressure gauge & G & DC Power regulator \\
\hline C & Tracking sensor & H & Parabolic dish reflector \\
\hline D & Sprocket and chain drive & I & Data logger \\
\hline E & DC motor & J & Thermocouples \\
\hline
\end{tabular}

\subsection{Heat Transfer Mechanisms}

PCM storage charging with hot water or oil utilizes the medium's sensible heat capacity, in which the amount of energy released per unit volume is relatively small. However, charging with saturated steam employs the latent heat released during its phase change. The condensate exits the PCM storage at temperatures close to the inlet steam temperature. The thermosiphon loop has to be flushed first to free any trapped air and filled $2 / 3$ of its volume with water. There is no expansion tank in this loop design. A boiling-condensing mode of heat transfer technique has followed to transport the heat from the receiver to the storage. Theoretically, the mass flow rate of the fluid circulating in the loop can be found by conducting a momentum balance around the loop (Dobson and Ruppersberg, 2007) and the heat transfer in the imbedded pipe is treated as 
film condensation in nearly horizontal pipes.

The mode of heat transfer between the stainless steel pipe and aluminum block is treated as a pure conduction between composite solids as shown in figure 2. This heat is analyzed using Fourier's conduction equations (3-5).

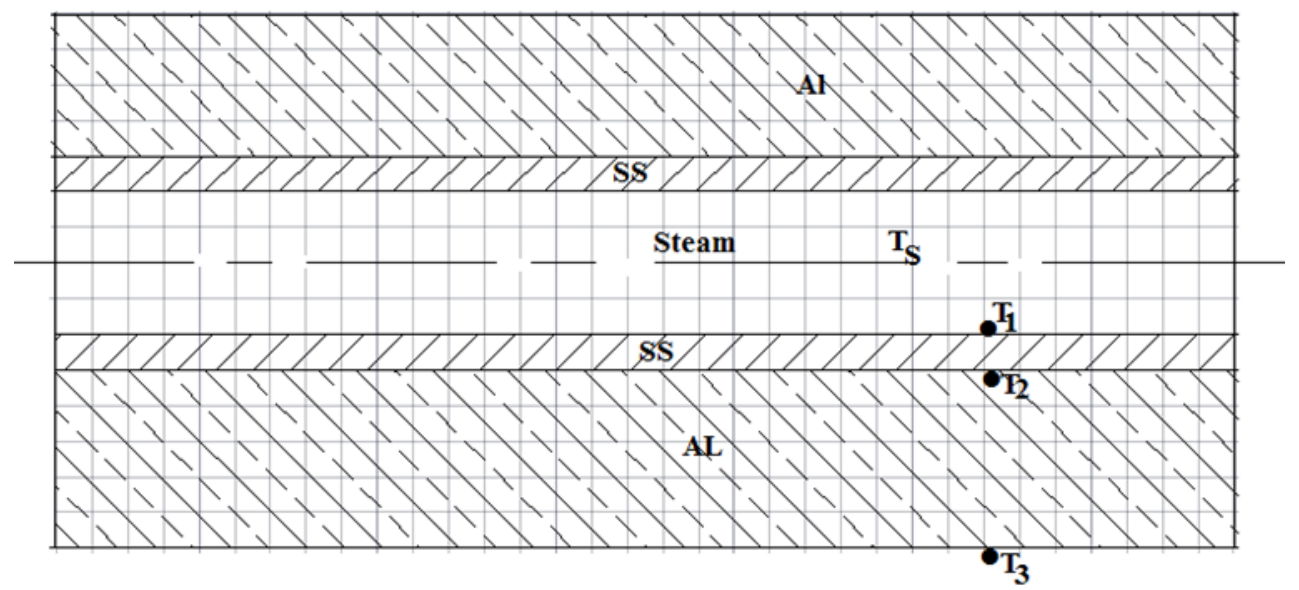

Figure 2. Composite materials of aluminum and SS.

Assuming small pipe wall thickness (L) compared to pipe diameter:

$$
\begin{gathered}
\dot{Q}_{\text {cond }}=-k A \frac{d T}{d x} \\
\frac{\dot{Q}}{A} \int_{0}^{L} d x=-\int_{T_{1}}^{T_{2}} k d T
\end{gathered}
$$

If the small variation in $\mathrm{k}$ has ignored the equation simplifies in to:

$$
\dot{Q}=\frac{k A}{L}\left(T_{1}-T_{2}\right)
$$

Where, $\frac{L}{k A}$ is the thermal resistance of the material.

The overall thermal resistances of the composite wall is treated in the same way as total series resistance of electric circuit. Assuming 2D geometry for simplicity: the fin and the plate temperature progress is the same and change in area (A) and thermal conductivity (k) with temperature is negligible, $\mathrm{T}_{3}$ (fin temperature) is then calculated by:

$$
T_{3}-T_{1}=\dot{Q}\left(\frac{L_{S S}}{k_{S S} A}+\frac{L_{A l}}{k_{A l} A}\right)
$$


In a heating plate temperature-time profile, the analysis of the heat transfer rate from the heating plate (frying pan) to the fins and from the fins to the PCM was analyzed using eq. (7 and 8) respectively (Dobson and Ruppersberg, 2007).

$$
\begin{aligned}
& \dot{Q}_{\mathrm{p}, f}=\frac{T_{p}-T_{f}}{R_{P, f}} \\
& \dot{Q}_{f, P C M}=\frac{T_{f}-T_{P C M}}{R_{f, P C M}}
\end{aligned}
$$

Theoretically, the temperature development of the fin is found by using eq. (9) and the heat transfer rate from the fin at temperature, $\mathrm{T}_{\mathrm{f}}$, to the $\mathrm{PCM}$ at temperature, $\mathrm{T}_{\mathrm{hp}}$, in the storage must equal to the heat transfer rate from the plate to the fin as shown in eq. (10).

$$
\begin{aligned}
& \frac{d T_{f}}{d t}=\frac{\dot{Q}_{\mathrm{P}, f}-\dot{Q}_{f, P c m}}{m_{f} c_{v, f}} \\
& \dot{Q}_{f, \mathrm{PCM}}=\frac{T_{f}-T_{P C M}}{R_{f, P C M}}=\dot{Q}_{\mathrm{P}, f}=\frac{T_{P}-T_{f}}{R_{P, f}}
\end{aligned}
$$

On rearranging of eq. (10), the PCM temperature simplifies to eq. (11). Figure 3 shows the COMSOL mesh of the PCM material adjacent to the fin.

$$
T_{P C M}=\frac{T_{f} R_{P C M, f}+T_{f} R_{f, \mathrm{PCM},}}{R_{P, f}+R_{f, P C M}}
$$

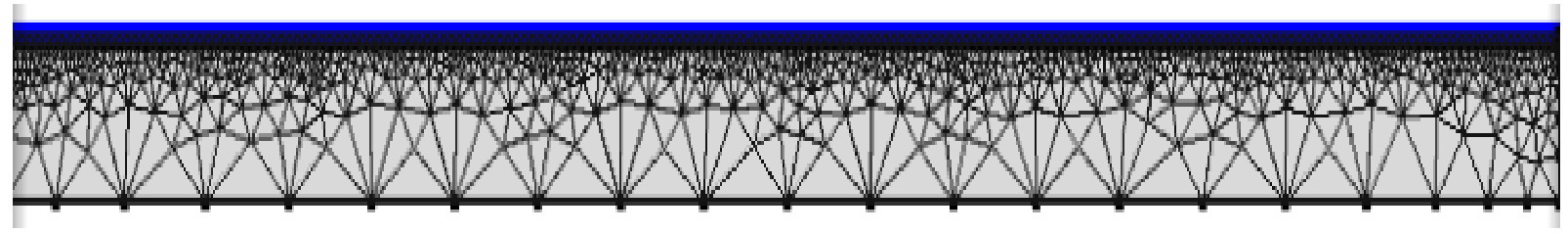

Figure 3. Mesh of PCM material during conduction charging.

\subsection{Thermal Performance}

The thermal performance of the system is given by the ratio of the useful energy stored to the energy incident at the concentrator's aperture. The storage energy is the sum of the energy stored in the PCM and in the aluminum fin. Therefore, the thermal efficiency of the system has computed by:

$$
\eta_{t h}=\frac{C_{A l} m_{A l}\left(T_{f}-T_{i}\right)+m \int_{T_{i}}^{T_{f}} C_{p} d T}{A_{a} I_{B}}
$$

Where, $\mathrm{cp}$ is the effective heat capacity of the PCM (eq.2) 
Both normal and diffuse radiation enters the aperture area of any solar collectors. However, using concentrating collectors only the direct radiation can focused on the receiver. In this paper, the thermal analysis of the system has performed only for its solid phase sensible heat-storing ability as it has not fully charged. The systems developed here reached $157^{\circ} \mathrm{C}$ of maximum temperature during the experiments of this study. Therefore, the thermal performance during these days has calculated $19 \%$. The performance of the system has affected mainly by the heat loss from the receiver.

\subsection{Insulation}

Aerogel and Rockwool insulations have used to insulate the storage and the steam pipelines respectively. The insulations maximum working temperature is about $650^{\circ} \mathrm{C}$, however, the maximum working temperature of the designed systems' have set to $250^{\circ} \mathrm{C}$ (by adjusting the pressure relief valve) and the design thickness of the insulation is $25 \mathrm{~mm}$ for the storage and $50 \mathrm{~mm}$ for the pipeline. The insulations thermal conductivity is $0.03 \mathrm{~W} / \mathrm{Km}$ and $0.07 \mathrm{~W} / \mathrm{Km}$ respectively and they have the same surface emissivity of 0.05 .

\subsection{Pipelines}

The size of the steam pipeline used has $10 \mathrm{~mm}$ outer diameter and $8 \mathrm{~mm}$ inner diameter with $1 \mathrm{~mm}$ thickness. The SS pipe has used as a pipeline in the heat transfer loop and as a heating element of the $\mathrm{Al}$ baking plate respectively. The pipe has 100bar design pressure and has used for 40bar working pressure give high emphasis on the safety. The pipeline used swagelok connectors and valves. A pressure gage has used to measure the pressure of the steam and regulated with the help of a safety valve that reliefs the pressure when it passed the pre-set value (40bar). The pipeline has flashed before the beginning of experiment to avoid air inclusion.

\section{RESULTS AND DISCUSSION}

\subsection{Modelling and Simulation}

COMSOL multi-physics 4.3 has used to simulate the storage charging process. The simulation work has run for 2D and 3D models. The simulation results showed the storage has fully charged in about seven hours, when it has heated by a $250^{\circ} \mathrm{C}$ continuously circulating steam. The simulation considers a constant loss of $15^{\circ} \mathrm{C}$ from the storage. For model simplicity, the fin in the COMSOL simulation used in figure $4(\mathrm{a}-\mathrm{c})$ has considered circularly rolled plate fins instead of the many cylindrical fins in the actual prototype. This fin assumption has an impact on 
lowering the overall charging time of the storage. The simulation shows the charging of the PCM sandwiched between two fins is very quick as shown in figure 4c, however, the PCM adjacent to the storage wall and bottom changes its phase very slowly. This simulation result suggests to half the dimension of the gap between the fin and the storage wall and bottom. Therefore, the PCM thickness between the fin and the sidewall and between the fin and the bottom wall should be $20 \mathrm{~mm}$. Moreover, it has found rolled plate fins charge the PCM quicker than rod fins. In addition to the PCM charging development, the simulation has also run to show the thermal resistance effect of the SS pipe wall on the Al plate as shown in figure 4d.

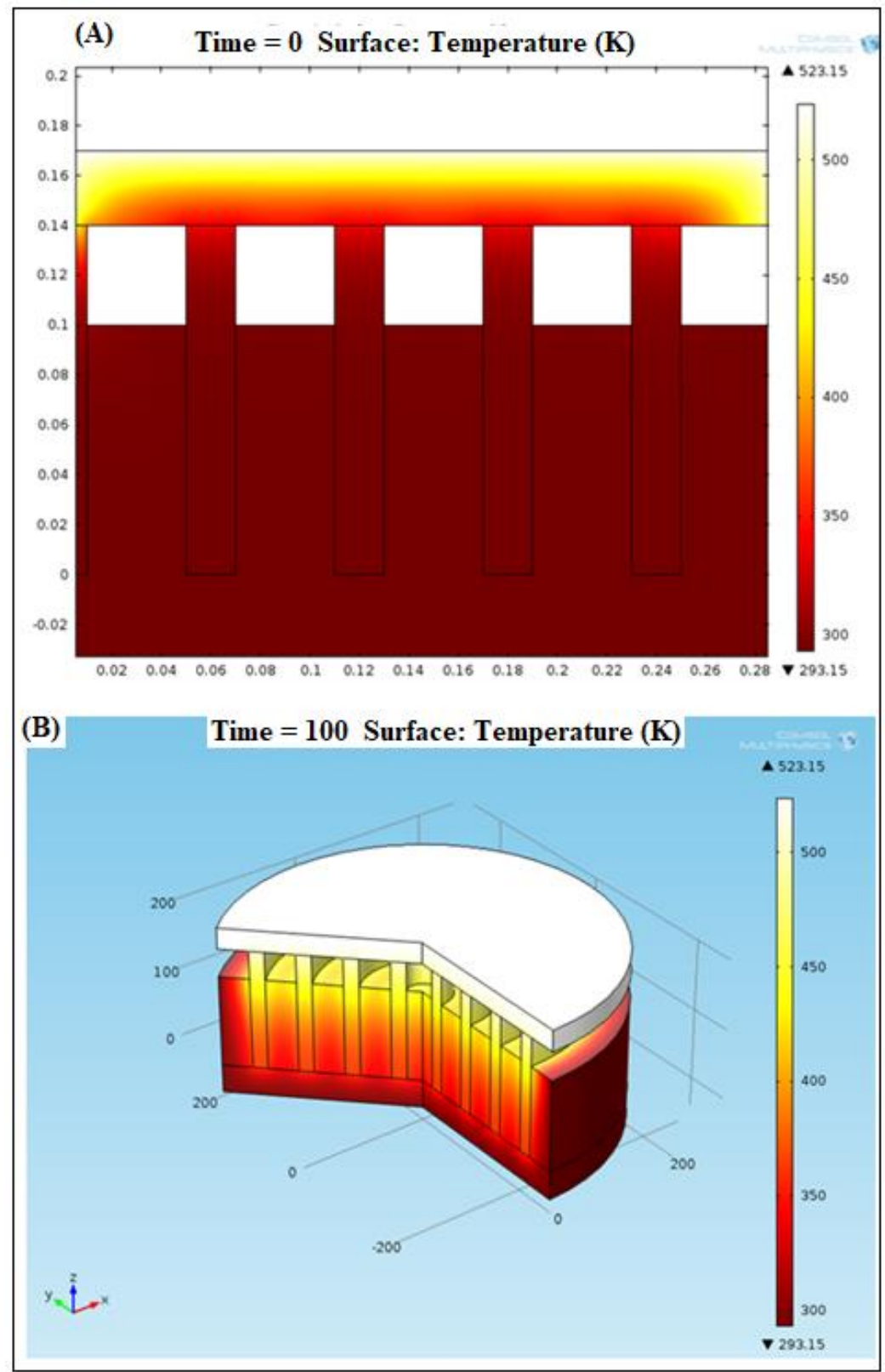




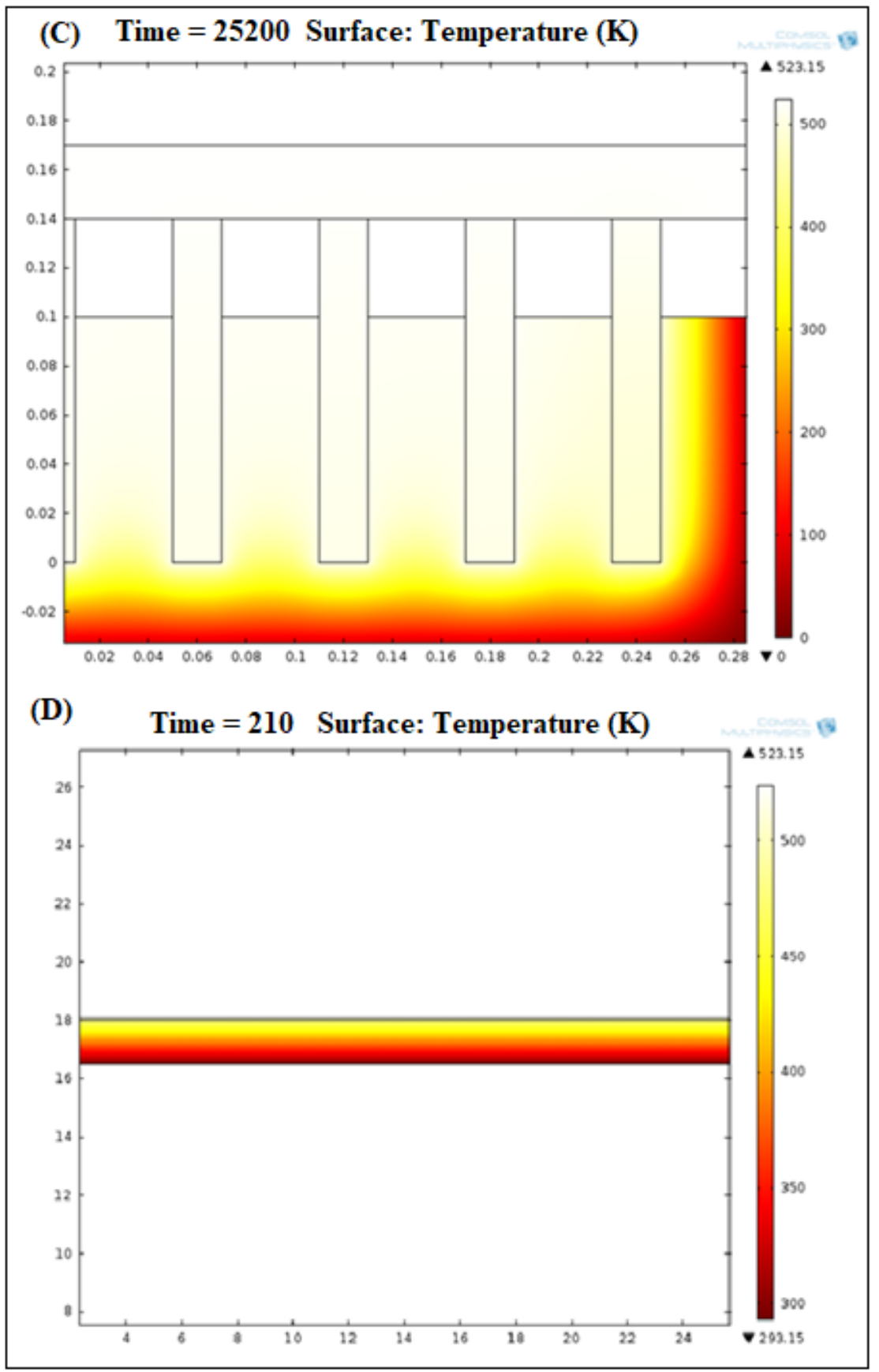

Figure 4. COMSOL simulation of PCM charging and heat transfer between SS and aluminum wall (a) beginning of phase change, (b) development of phase change after 100 seconds, (c) final phase change and impact of end wall design dimensions and (d) the resistance of SS in heat transfer

\subsection{Experimental Test}

The polar mounted concept eases the tracking mechanism in the secondary axis and the fixed 
focus receiver, has found suitable for steam generation. The steam circulates between the evaporator (receiver) and $\mathrm{Al}$ plate (condenser) in a closed loop naturally. The steam carries the heat from the receiver and drops it on the aluminum plate. The fins attached to this plate in return carries this energy to the PCM storage. The test unit of this paper is shown in figure 5.
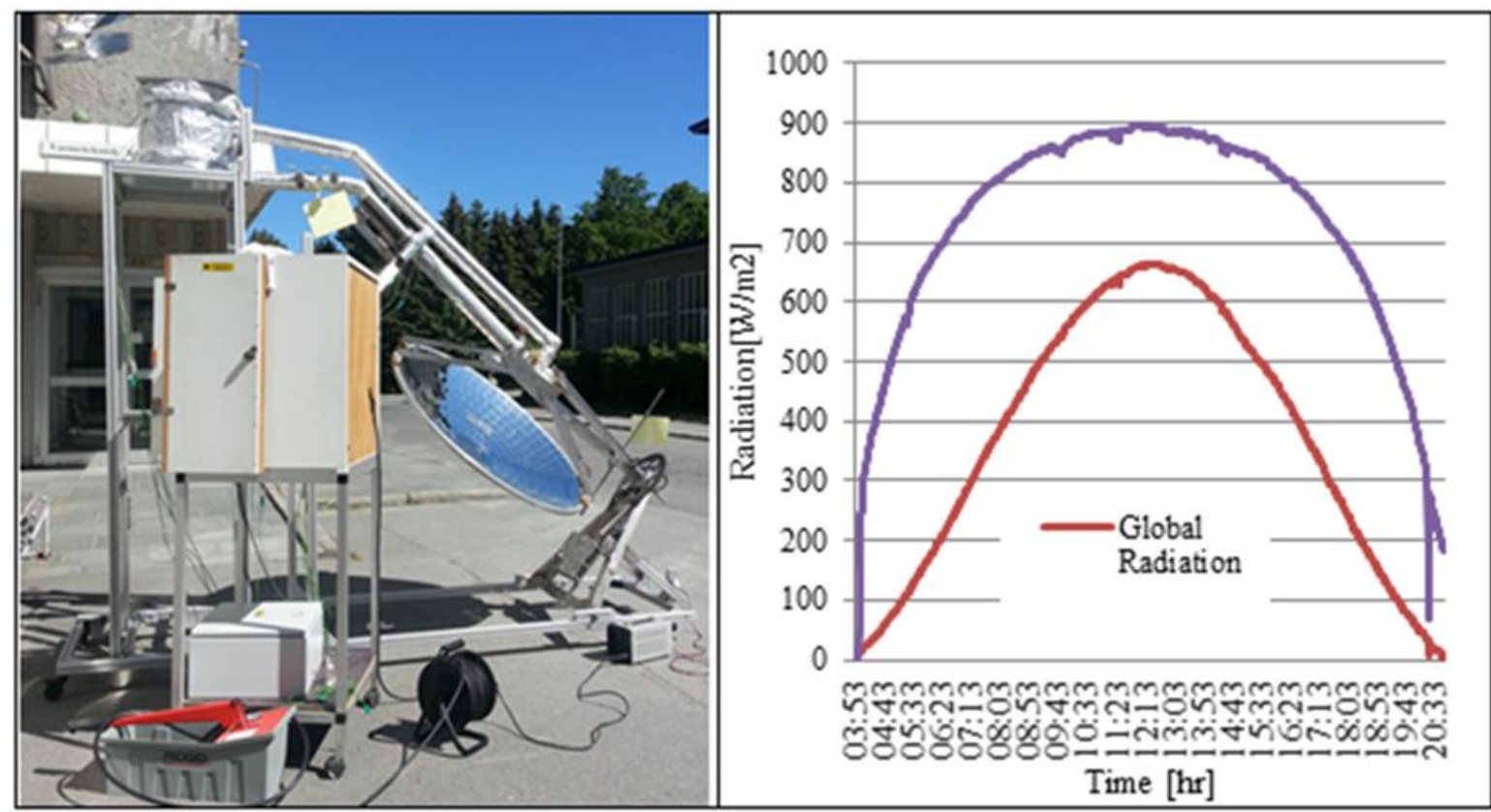

Figure 5. Parabolic dish with PCM storage Trondheim's global and normal beam radiation for 25-07-2013.

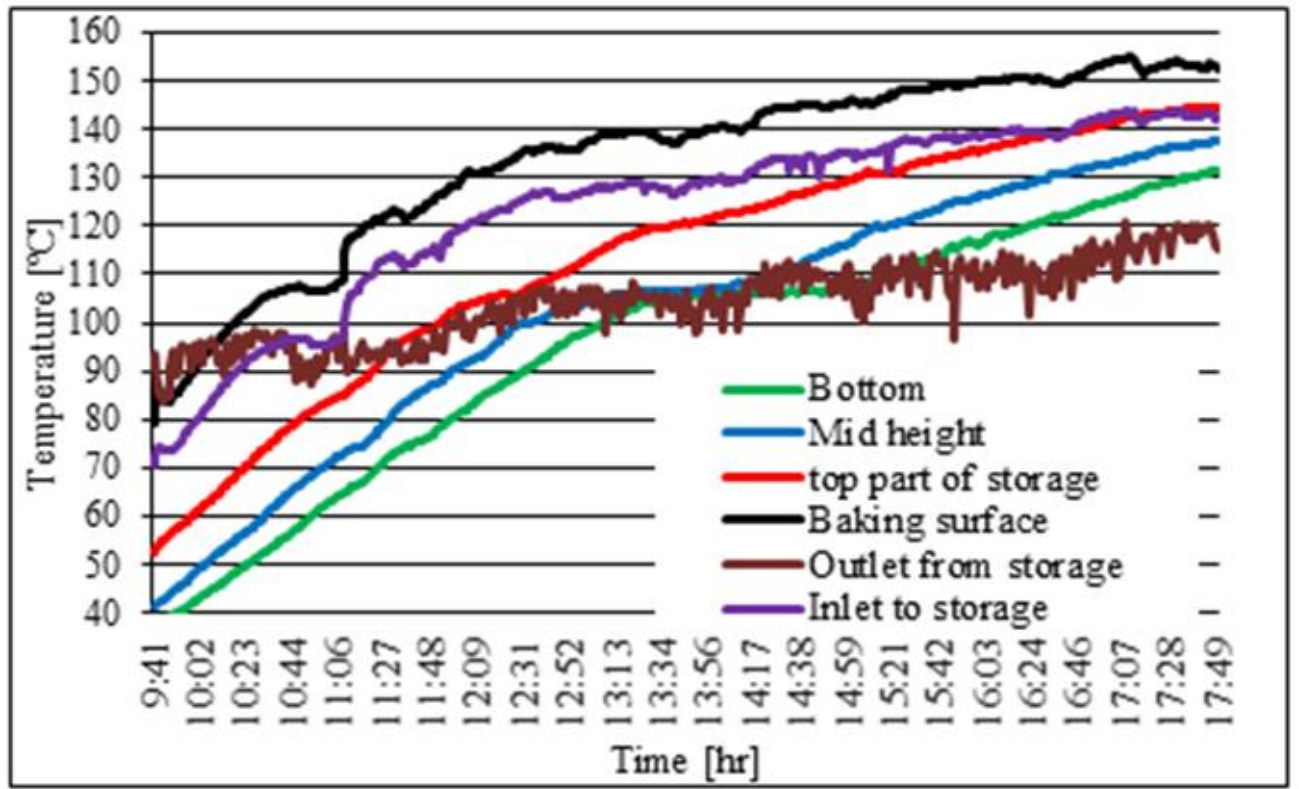

Figure 6. PCM charging practice. 


\subsubsection{Charging of Thermal Storage Using Natural Sun}

Solar reflector when starts focusing the solar radiation on the receiver, the water inside the receiver start boiling and a vapor at low temperature starts circulating. The stagnation temperature of this unit could not reach the melting point of the PCM. The storage has charged in successive days using the advantage of the PCM material's heat retention ability. However, this did not help to charge it fully; this is probably due to the losses at the receiver. The maximum temperature attained in the PCM storage had reached a temperature range of $130^{\circ} \mathrm{C}$ to $157^{\circ} \mathrm{C}$ as shown in figure 6.

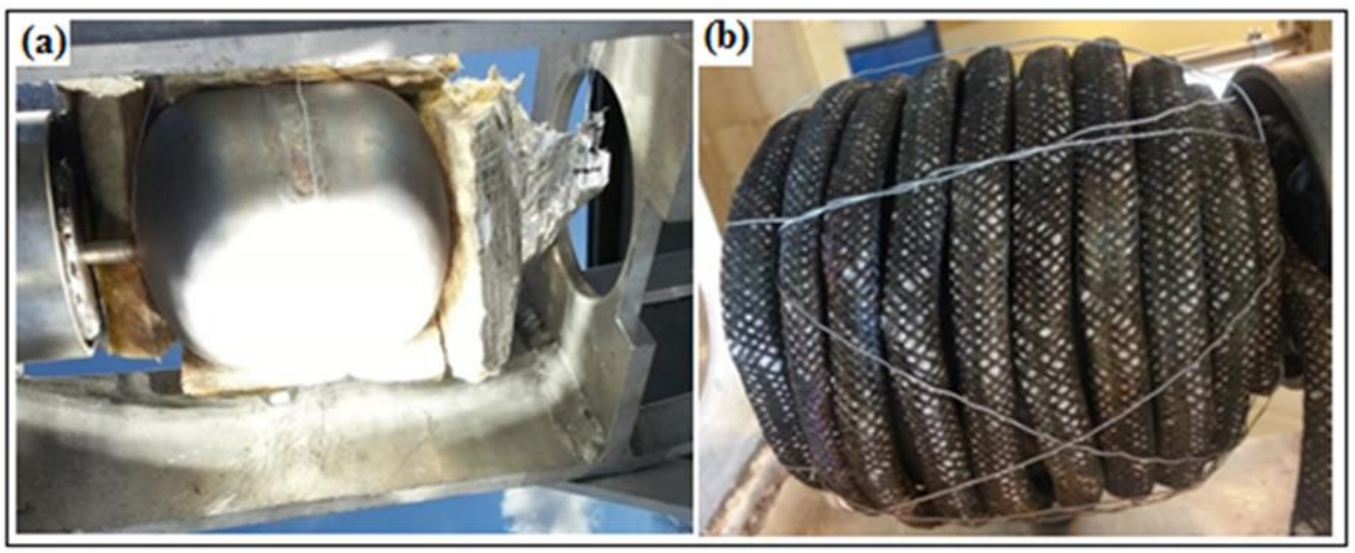

Figure 7. Receiver of a parabolic dish collector, (a) solar test, and (b) heating element (before insulation).

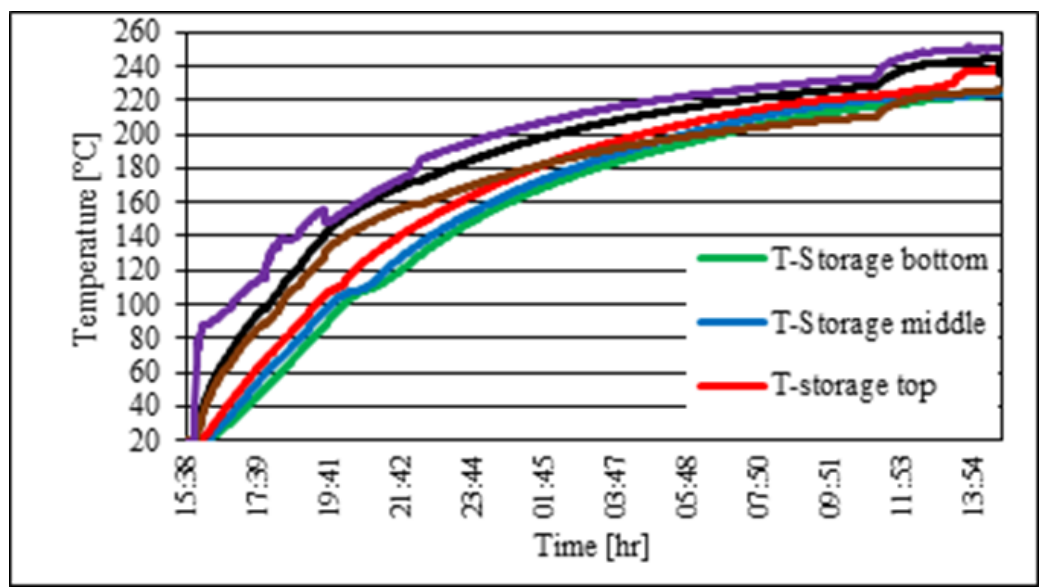

Figure 8. Artificial charging of PCM storage.

\subsubsection{Charging of PCM Storage Artificially}

An artificial heating element has coiled around the receiver in order to obtain a regulated temperature at the receiver that is capable of generating steam at elevated temperature (Fig 7). 
The heating element is set to maximum temperature, $450^{\circ} \mathrm{C}$, at which it was delivering an average power of $700 \mathrm{~W}$ to the receiver which is equivalent to the solar power supply obtained from $1.2 \mathrm{~m}$ parabolic dish concentrator with $80 \%$ optical efficiency and $800 \mathrm{w} / \mathrm{m}^{2}$ average beam radiation. PCM storage took about 8 hours of phase change duration. The temperature development of the steam and the PCM during the charging process are shown in figure 8 .

The experimental result shows a close resemblance to the simulation result of charging time. This indicates the input power at the receiver is small and it must increase by using larger aperture area in order to reduce the charging time.

\section{CONCLUSION}

In this paper a concept of steam based heat storage charging by using polar mounted solar concentrator is developed and demonstrated. Heat is transferred by using thermosyphon principle, with water as the working fluid at about 35-bar pressure. Vapor is generated in the absorber at the focus point of the parabolic concentrator and it condenses in a coiled tube of SS embedded in the $\mathrm{Al}$ plate. The plate has heat-conducting rods extending into latent heat storage ("solar salt", Nitrate mixture). A boiling/condensing natural circulation loop (thermos syphon) is feasible with water as the heat transfer fluid. Because of the small water volume used in the system, the high pressure become manageable but still it required high quality pipe and valve components. The system can be optimized with respect to losses in the heat transfer loop, in particular at the absorber. The absorber is a spherical boiler in a fixed position, with the solar illuminated area moving from one side to the other during the daily sun tracking.

\section{ACKNOWLEDGEMENTS}

Authors duly acknowledge the research support of EnPe I and cooperation for using laboratory and research facilities of the Department of Mechanical Engineering, Mekelle University and Energy and Process Engineering of Norwegian University of Science and Technology (NTNU).

\section{REFERENCE}

Abduljalil, A. Al-Abidi., Sohif, M., Sopian, K., Sulaiman, M.Y \& Abdulrahman, Th. Mohammad. 2014. Experimental study of melting and solidification of PCM in a triplex tube heat exchanger with fins. Energy and Buildings, 68:33-41. 
Alessandro, F \& Sauro, F. 2013. Experimental analysis of Closed Loop Two Phase Thermosyphon (CLTPT) forenergy systems. Experimental Thermal and Fluid Science, 51:302-311.

Dobson, R. T \& Ruppersberg, J. C. 2007. Flow and heat transfer in a closed loop thermo syphon: part I- theoretical simulation. J. Energy in South Africa, 18:32-80.

Foong, C, W., 2011, Experimental and numerical investigations of a small scale double-reflector concentrating solar system with latent heat storage, $\mathrm{PhD}$ Thesis, Norwegian university of science and Technology (NTNU), P: 36-61, Published

Hussein, H.M.s., El-Ghetany, H.H \& Nada, S.A. 2008. Experimental investigation of novel indirect solar cooker with indoor PCM thermal storage and cooking unit. Energy Conversion and Management, 49(8):2237-2246 (DOI: 10.1016/j.enconman.2008.01.026).

Kuravi, S., Trahan, J., Goswami, D.Y., Rahman, M.M \& Stefanakos, E.K. 2013. Thermal energy storage technologies and systems for concentrating solar power plants. Prog. Energy Combust. Sci., 39:285-319.

Okello, D., Ole, J. N \& Eldad, J.K. B. 2014. Experimental investigation of thermal destratification in rock bed TES systems for high temperature applications. Energy Conversion and Management, 86:125-131.

Robynne, E. M \& Groulx, D. 2014. Experimental study of the phase change and energy characteristics inside a cylindrical latent heat energy storage system: Part 1consecutive charging and discharging. Renewable Energy, 62:571-581.

Taha, K. A \& Rahman, M. M. 2014. Comparison between the single-PCM and multi-PCM thermal energy storage design. Energy Conversion and Management, 83:79-87.

Tanvir, E. A. Jaspreet, S., Dhau, D., Yogi, G \& Elias, S. 2015. Macro-encapsulation and characterization of phase change materials for latent heat thermal energy storage systems. Applied Energy, 154:92-101.

Zhang, L., Fan, L., Hua, M., Zhu, Z., Wu, Y \& Yu, Z. 2014. An indoor experimental investigation of thethermal performance of a TPLT-based natural circulation steam generator as applied to PTC systems. Applied Thermal Engineering, 62:330-340. 